Article

\title{
Cartesian Dualism: An Evaluation of Wireduan and Gilbert Ryle's Refutations
}

\section{Olusegun Steven Samuel}

\begin{abstract}
This paper takes a philosophical look at how the views of Gilbert Ryle and Kwasi Wiredu can be used to resolving the mind-body problem located in Rene Descartes' philosophy. The common sense account of the mind-body theory was first systematically carried out by Descartes. To him, mind and body do not only exist, they also interact. Through his notion of clear and distinct ideas, Descartes infers the existence of the mind as a thinking substance. Unlike the mind, whose character is thought, the body for Descartes is an extended thing. He insists that the point of interaction is the pineal grand, which God has worked out from the point of creation. Today, the view that body and mind interact has generated some controversies. Ryle argues that Descartes has made a category mistake by interpreting mind as a distinct substance. For Wiredu, in Akan thought system, mind does not go to constitute a person. Thus Ryle and Wiredu tend toward materialism when they argue that the source of consciousness is the brain, rather than the mind. This paper explores the claims of these philosophers: Descartes, Ryle and Wiredu. I stress that Ryle and Wiredu's views do not resolve the Cartesian problem. The paper concludes that unless the problem of the source of consciousness is tackled, the mind-body problem cannot be adequately resolved.
\end{abstract}

Key words: Mind-body problem, category mistake, dualism, person

\section{Introduction}

Whe issue of mind-body is as old as the history of Ancient Greek Philosophy. This problem can be seen in the Pythagoreans as well as the philosophies of Socratic-Platonism. The so called-mind-body problem refers to the question of whether man's consciousness can be reduced to psychological interpretation, scientific laws or some sorts of inner disposition of a ghostly or spiritual substance.

However, the postulation of a mind as distinct from the body has found supports in the worldviews of not only religious scholars, but philosophers as well. Among these thinkers that subscribe to the working of the mind, I find Rene Descartes more systematic. Thus this paper is directed 
towards examining his claim that mind and body exist as two distinct substances.

This paper is interested in showing the plausibility of Rene Descartes mind-body interaction, a view that has been considerably examined by scholars like Gilbert Ryle and Wiredu among other thinkers. However, I am interested also in seeking or knowing to what extend does the Akan conception of mind in Wireduan philosophy and Gilbert Ryle's idea of category mistake address the inherent problem of Cartesian dualism.

Be that as it may, I believe that a thorough analysis of the root of consciousness is imperative for the discourse of this magnitude. Therefore to achieve my aim, this paper is structured into four parts. The first part is an overview of Rene Descartes' idea of mind and body: a view which led him into dualism. The second part seeks insight into Gilbert Ryle's critique of Descartes along the path of linguistic interpretation, which he calls the "category mistake". The third section looks at the problem of man's composition in Wireduan view. Here, the characteristics of a person and what constitutes his personhood is examined. The final section looks at the issue of consciousness anew. For these sections, I seek therein, the plausibility's of these thinkers' positions.

\section{Cartesian Dualism: An Overview}

Rene Descartes, the father of modern philosophy, is best known for his theory of mind-body dualism, although, he appears to be more idealistic than dualistic in his idea of the self. To us, and like for Descartes, the mind and body seem to be distinct entities when we look at it via our senses, but the issue of their interactions pose a big problem not only to Descartes, but to us all.

Descartes, in his popular work titled Meditation, holds that mind and body are distinct substances which interact. The mind to him can be found in a person, so also is the body. In his explanation of the self, Descartes' assertion cogito ergo sum (I think therefore I am) establishes that human existence lies in the act of consciousness. Here, the dictum "I think", is the major defining characteristics of human existence.

However, Descartes avers that the root of consciousness is the mind, rather the brain. That is, the mind, in his understanding, is the "self", who performs the act of consciousness such as thinking, imagining, doubting, reflecting, and willing. Against this backdrop, Descartes describes it as mental, thought and non-spatial in character. What is mental or non-spatial event? This is clearly answered by Nigel Warburton, who writes: "Mental aspects are such things as thinking, feeling, deciding, dreaming, imagining, and wishing and so on."1 Thus Descartes posits that mental elements cannot be extended in space. The nature of the mind is therefore thought res cogitans.

${ }^{1}$ N. Warburton, Philosophy: The Basics (London: Routledge, 1999), 131. 


\section{CARTESIAN DUALISM}

Descartes, unlike radical idealists like George Berkeley, holds that aside the existence of a thinking thing (mind or the self), body also exists. To him, his body includes: his face, arms, and other members composed of bones and flesh including human's brain. All these are, in his view, divisible, spatial and capable of being extended. Descartes writes:

By body, I understood all that which can be defined by a certain figure. Something which can be confined in a certain place, and which can fill a given space in such a way that every other body will be excluded from it; which can be perceived either by touch, or sight, or by hearing or taste. ${ }^{2}$

Descartes' excerpt shows that the body is distinct from the mind. What this implies is that they are two distinct substances. But these questions must be asked: How do I explain a non-spatial mind being trapped in a spatial body? Is this not a language misrepresentation? Is there truly a mind? How accurate is Descartes' claim that mind is responsible for thought?

These questions do not mean anything problematic to Descartes. In his view, aside the ground that these substances are distinct, they influence each other. This agrees with our common sense worldview. For instance, If one feels like jumping up (feeling, being a mental event), the body muscles respond to the mental event (one jumps up), although, it may be granted that this may not happen in all circumstances. A good instance is when one is sick, where one desires to stand up but could not. There is to be noted here, two types of event: mental (internal) and physical (public) events.

To Descartes, the point of interaction is somewhere close to the brain (the pineal gland). This interaction to him cannot be explained through the law of physics, because this will mean that we are trying to reduce the mind to the brain. This position for him will render the substantial quality of mind useless. Thus Descartes favours the Divine's interpretation, rather than the scientific ones. He harps that he is so certain about this since God would not want to deceive him. The justification for the existence of two substances, for Descartes, is therefore based on his belief in God's infallibility. It is therefore God that makes the interaction possible.

I do not think that Descartes' explanation of mind-body, the point of interaction (the pineal gland) and his view that mind is the source of consciousness have been clearly and distinctly conceived by him. In fact, the problem of something non-extended touching something extended seems absurd. It is therefore the attempt to resolve the problem of Cartesian dualism that Ryle and Wireduan arguments seem significant.

2 R. Descartes, "Meditations," in Joseph Margolis ed., An Introduction to Philosophical Inquiry: Contemporary and Classical Sources (New York: Alfred. A. Knopf, Inc, I968), 279. 


\section{Gilber Ryle's Category Mistake: A Critique of Cartesian Dualism}

To begin with, it should be noted that Descartes believes in the existence of the mind as well as the body. Writing on his account of the mind, Descartes avers:

I considered that I was nourished, that I walked, that I felt, that I thought, and I referred to all these outcome to the soul. ${ }^{3}$

The soul and the mind are taken to be the same for Descartes, and as such, one also cannot meaningfully separate the res cogitans (thinking thing, the mind) and res extensa (the extended thing, or, perhaps, the body). This is what Descartes believes to be the two parts of a person. A person therefore is a mind and a body. The self is the conjunction of a mind and a body. He also grants that the mind or soul can outlive the body. This appears to be an argument for the immortality of the soul.

Gilbert Ryle's philosophy is therefore a refutation of Descartes' claim that a person is a mind and a body, or a duality of mind-body. For Ryle, it is better to hold that a person is a body or is a mind, but not both. What Ryle is rejecting is Descartes' argument that a person is both mind and body. Ryle reiterates:

I am not for example, denying that there occur mental processes. Doing long division is a mental process and so is making a joke. But I am saying that the phrase "there occur mental processes" does not mean the same as "there occur physical processes", and therefore, that it makes no sense to conjoin or disjoin the two. ${ }^{4}$

Here, it should be noted that Ryle is not in favour of dualism. He believes that the fact of consciousness can be linked to the brain. For this reason, he stresses that Descartes has made a category mistake. He describes it as the "Dogma of the Ghost in the machine." 5 What Ryle is saying here is that Descartes represents the facts of mental life as if they belong to one logical category, where in the actual sense they belong to another. That is, he misrepresents the substance responsible for conscious or mental activities. Instead of positing that the human brain is the root of consciousness, Descartes invented the mind. Ryle stresses that there is no need to invent another substance (mind).

\footnotetext{
${ }^{3}$ Ibid., 278.

${ }^{4}$ G. Ryle, "Descartes' Myth" in Joseph Margolis ed., An Introduction to Philosophical Inquiry: Contemporary and Classical Sources, 316.

${ }^{5}$ Ibid., 31.
} 
Thus Ryle gives some analogies to show that there is a linguistic misinterpretation in Descartes' conception of a person. Rather than supporting dualism, Ryle favours a form of reductive materialism, where the human mind is reduced to the brain. What this means is that, instead of postulating another substance (a mind), Descartes should be made to see that a ghost cannot be in a machine. That is, to say that a mind exists as a substance will be meaningful, if and only if it is conceived as the brain, rather than something different from it. Hence it is either the self is a mind or it is the brain or body, but not mind and body.

Embracing a form of materialism, Ryle argues that what is responsible for "thought," a mental event, is the brain. Here, mental event exists, not as a distinct category, but as a product of the brain. This vision is clearly captured in J.J.C Smart's assertion: "mental processes are brain processes." 6

But we must ask: Has Ryle's account dealt accurately with the mindbody problem in Descartes' philosophy? Is reductive materialism itself free from criticisms? Is Cartesian mind-body problem only a linguistic problem? Is Descartes' notion of God also a linguistic problem? This paper shall attempt concise solutions to some of these problems or issue raised.

\section{Kwasi Wiredu's Conception of a Person: A Survey of the Akan Conception of Mind}

What constitutes the human person in Descartes' philosophy? How does Wiredu see the nature of a person in his critique of Descartes' dualism? How many metaphysical elements exist in Wireduan philosophy of the mind? Can Wiredu's account of the mind resolve the Cartesian mind-body problem?

These questions are robust, and in this paper, I cannot boast to have dealt with them conclusively. However, attempt, and only an attempt; will be made toward throwing more light on them. This is not to say that this paper is only interested in amusing us, rather it is directed at some problems that assail us. To my mind, an exercise in philosophy should do more than only engaging in a descriptive course; rather a concrete effort must be taken to remove our worries, pains, difficulties and so on. Let us return to Wiredu's philosophy of mind.

Wiredu, in my opinion, belongs to another culture distinct from that of Ryle and Descartes. One may therefore be tempted to argue that his position on this matter may not be suitable for addressing this problem. Whether this is the case or not, a concise clarification of his view is needed for a comparative philosophy to attain its merit.

Briefly conceived, Wiredu in his Akan Concept of Mind posits tripartite characteristics that go to constitute a person. Unlike Descartes that holds that mind and body are the only two substances that make up a person, Wiredu argues that the word "mind" which is a non-substance entity in the Akan

${ }^{6}$ J.J.C Smart, "Processes, Sensations and Brain," in Introduction to Philosophical Inquiry: Contemporary and Classical Sources, 320. 
thought does not go to constitute a person. To him, what constitutes the parts of a person include: body (Nipadua), a life giving entity (Okra), that which gives a person's personality it force (Sumsum), blood (Mogya) and that which is responsible for one's personality cast (Ntoro). The three major elements in a person, in Wiredu's view, are the Nipadua, Okra and Sumsum, although Mogya and Ntoro are often mentioned in a discourse on personhood.

The Okra, for him, is the most significant part of a person. $\mathrm{He}$ describes it as a quasi-physical entity which has para-physical qualities. What this means is that the "okra" is neither physical nor spiritual, but both in quality. Unlike the Western conception of person found in Descartes' view, the mind, to Wiredu, is not an entity or a substance. This invariably means that only a substance can be a major element of a person.

Consequently, Wiredu considers the issue of consciousness and its root. Here, Wiredu supports the materialist account of consciousness. To him, the seat of thought popularly shared among the Akans is the brain. Thus he argues that thinking cannot go on in a human being without the brain. ${ }^{7}$ Here, one may want to accept Ryle's position that Descartes had made a category mistake for supposing that it is the mind that thinks. To strengthen his position, Wiredu informs us that certain damages to the brain will impair thought. As one may see, just as we have noticed in our daily lives, Wiredu's explanation at this point shows clearly that there is a link between brain processes and consciousness.

Since Wiredu makes a reference to "okra", which is, "quasi-physical entity" in a person, that is, something which has both spiritual and physical properties, one may ask: Are mental events non-spiritual? If yes, what constitutes the nature of a spiritual substance?

However, Wiredu; having granted that mind is not an entity, stresses that when linguistically assessed, it could be said to mean "thought" (adwene" in Akan language). Thought for him has its source, and this is the brain. He avers that it is the brain that does the thinking. This is captured thus:

As to the instrument of the mechanism of thought, it is clear from the speech of the Akans that it is the brain, 'adwene, that has this status. They know that thinking cannot go on in a human being without the brain, the certain injuries to the brain will impair thought and that generally there is a correlation between brain activity and thinking. ${ }^{8}$

In whatever way one looks at it, Ryle and Wiredu's arguments attack Cartesian dualism on the linguistic as well as empirical ground. However, why Ryle supports a pure materialistic account (a form of reductive materialism),

7 K. Wiredu, "The Akan Concept of Mind," in Ibadan Journal of Humanistic Studies, 3 (October 1983), 117.

${ }^{8}$ Ibid., 130. 
Wiredu grants that a quasi-phsical entity exists in Akan thought. The questions we must raise include: Is there a single conception of personhood that must be accepted by us? If not, how come do we see problem(s) in Cartesian philosophy? Are we justified in using the category of Western Philosophy in appraising the philosophy of the East or Africa? If not, why then the comparison? And finally, to what extent does the Akan conception of mind and category mistake of Wiredu and Ryle respectively, address the inherent problems of Cartesian dualism.

\section{Cartesian Dualism: An Evaluation of Wireduan and Ryle's Refutation}

Descartes, Ryle and Wiredu have impressed us by their different accounts of the nature of a person. Thus there are many issues to be raised in this discourse. The issue of personal identity, the mind-body interaction problem, the problem of the source of consciousness, the view that a substance can be quasi-physical, the problem of justifying the existence of God, the issue of linguistic interpretation, the problem of reductionism, problem of immortality of the soul and so on.

As we have noted above, this paper does not claim to have dissolved these problems. However, we are interested in putting forward the thesis that any attempt to resolve these conflicts must start from the origin of consciousness. We may ask: What is the root of these problems that we are confronted with? Without mincing words, this problem is the issue of consciousness. It is because Descartes does not believe that brain is the source of consciousness that prompts him to assert that it is the mind that thinks. A close look at Ryle and Wiredu's view on this problem show that for them, the source of consciousness is the brain. As the matter now stands, it is until we have resolved this matter that we can fully deal with the above problems. To corroborate my view, J Nagel writes: "When the problem of consciousness is solved, the mind-body problem will also be solved." I agree unconditionally to this submission. In fact, Nagel maintains that it is the issue of consciousness that makes the mind-body problem interesting. For me, we do not do philosophy because we want to be amused, rather we are faced with a serious task, if not solved; would render our live hopeless. My aim therefore is to contribute in resolving Descartes' mind-body problem.

Reubel Abel stresses that the mind-body problem exists because the state of consciousness interacts with the state of corporeal body. ${ }^{10}$ This interaction has not been considerably resolved by Descartes. How can something outside space relate with something in space? This, in fact, is a mistake. The mind, if even granted existence, fails immediately it is accepted that it is trapped in the body. But one may ask: Is there anything difficult for

9 J. Nagel, "What is it like to be Bat?," in Mortal Questions (New York: Cambridge University Press, 1979), 165-166.

${ }^{10}$ See R. Abel, Man is the Measure (New York: Free Press, 1976), 203. 


\section{O. SAMUEL 163}

God to do? Religious people may find the Cartesian analysis useful, on the ground that God has the power to do all things. However, the atheists may not be persuaded that God exists. In fact, the construction of personhood in the Cartesian sense assumes that God exists. The justification for God's existence which Descartes employed (an ontological argument) is limited in its persuasive intent. He sees God as the perfect conceivable being. This argument will only be persuasive to those believe that there is a need to postulate an unlimited being or a perfect being.

In fact, Descartes believes that the mind exists because we have internal dispositions. One must agree that these dispositions are mental. How then could a physical brain produce them? To Ryle and Wiredu, this can adequately be answered through brain processes. To them, if there is brain damage, consciousness will cease or mental activities will stop. To us, science has done considerably well in this regard, but this is not a conclusive ground to jettison the claim that mind exists. There is a need to ask: Is there any empirical proof to substantiate that the act of consciousness is the activity of the brain? Or is consciousness a physical process of the brain?

To our mind, this question can be accounted for by pointing to this or that man. However, there has been no empirical justification for this, because a close examination of the brain will not show any signs of conscious events. For example, when we feel pain, a look at the brain does not empirically show us pain. It is therefore probable to hold that another element may be responsible for this act of consciousness. This gives credit to Imant Baruss' assertion that materialism (eliminative or reductive) cannot fully explain matter, let alone subjective experiences (internal will). ${ }^{11}$

Let us become a little more skeptical. How do we know that brain thinks? The plausible account we can give (as in the case of Ryle and Wiredu) is that (i) it is empirical (ii) language of science accounts that it does, (iii) it is experiential. This leads us to ask: Can the language of science capture everything? By everything, we mean both physical and non-physical elements. To say that everything is physical means that " $\mathrm{X}$ " to be physical must obey the physical causal laws, and as such, everything $(X)$ is causally deterministic. Against this, man's intention, will and psychological nature have shown that we are not absolutely subjected to the law of nature. This point or may lead to the conclusion that Ryle's materialism is to be critique.

This is not all, if the "okra" is quasi-physical, how does Wiredu know this? The solution is simple: Wiredu fails to observe that linguistic interpretations are socially based. If the "Okra" is in us, how can we prove its existence? Having granted that "Okra" changes its nature, the best that Wiredu could say that we may grant, is that, meaning of terms are derived through communal solidarity, and by implication, there is no universal mode of doing or acting. Hence to refute the notion of mind in Akan thought system (as we

11 See I. Baruss, "Can we consider matter as ultimate reality? Some fundamental Problems with Materialist Interpretation of Reality," in Ultimate Reality and Meaning: Interdisciplinary Studies in Philosophy of Understanding, 16:3-4 (1993), 245-254. 


\section{CARTESIAN DUALISM}

found in Wiredu), is not the same as to say that mind in Descartes' philosophy does not exist, otherwise Wiredu will be equivocating. Descartes and Wiredu are trading their stocks at different markets. To say Wiredu's rejection of the mind in Akan thought is a critique of Cartesian dualism is to invariably involve oneself in an incommensurability of discourse. On this ground, mere refutation of the mind in Akan language does nothing to harm Cartesian philosophy.

Maybe, we should look at the issue of Ryle's category mistake anew. The core of this refutation is that mind should be taken out of the discourse of personhood. This brings to our mind quickly, the practice of yoga, soul-travel, day-dreaming, introspection, clairvoyance as well as telepathy. Are these activities the product of the brain? If it is granted that these activities are real, then the claim that they are the product of the brain will be baseless. However, it is one thing for us to claim that something exists, but it something else to show that they in fact do. Here, we have little competent, but there is a critical point to it. If $\mathrm{Mr}$ " $\mathrm{A}$ ", "B", "C" and "D" claimed that they practice such activities like telepathy and clairvoyance, and provide some evidences. Are we to grant that they do? In fact, many accounts have been given in the traditional African religion to support telepathy, yet we are still skeptical to the certainty of these claims. Why?

The question whether minds exist is the core of this dispute. No doubt, all have granted that the body exists. Of course, we have also granted that brain thinks. We never consider it necessary to refute these claims. The reason for this is simple: it is open to public assessment. To my mind, even if we all believe that brain thinks, we have no clear justification for this. It is not verifiable. As one may seek for a justifiable ground for ascertaining that brain thinks, it is needed to show empirical support for this. Since the standard of measurement of consciousness is openness, I doubt whether behaviourism has considerably resolved the matter. In my view therefore, the issue of consciousness is a recondite matter that scientists have not fully addressed. Until this problem is resolved, the Cartesian mind-body will be with us.

\section{Conclusion}

My attempt in this paper has been a critical evaluation of Ryle and Wiredu's critique of Cartesian dualism. The paper opened anew the issue of consciousness as the major bane of mind-body problem. I posited that effort should be made by scientists to re-investigate this matter anew for the materialist interpretation of personhood, has not fully resolved the problem in Descartes' philosophy of mind and body.

The intents of this paper not only addressed some of the militating problems of the Cartesian dualism, but also raised are some other fundamental questions that are associated with it. However, I do not hold that these problems have been resolved whether in this paper or somewhere else, rather I flagged the course for admitting "mind" into personhood conceptual box. This, to me, would give room for linguistic plurality, in the face of modern reductionist attitude. 
It is my conclusion that there is a concrete need to examine the issue of consciousness afresh because we are wont to believe that brain thinks and mind reflects; a position which is controversial.

Department of Philosophy, Lagos State University, Nigeria

\section{References}

Abel, R., Man is the Measure (New York: Free Press, 1976).

Baruss, I., "Can we consider matter as ultimate reality? Some fundamental Problems with Materialist Interpretation of Reality," in Ultimate Reality and Meaning: Interdisciplinary Studies in Philosophy of Understanding, 16:3-4 (1993).

Descartes, R., "Meditations," in Joseph Margolis ed., An Introduction to Philosophical Inquiry: Contemporary and Classical Sources (New York: Alfred. A. Knopf, Inc, I968).

Nagel, J., "What is it like to be Bat?," in Mortal Questions (New York: Cambridge University Press, 1979).

Ryle, G., "Descartes' Myth" in Joseph Margolis ed., An Introduction to Philosophical Inquiry: Contemporary and Classical Sources.

Smart, J.J.C, "Processes, Sensations and Brain," in Introduction to Philosophical Inquiry: Contemporary and Classical Sources.

Warburton, N., Philosophy: The Basics (London: Routledge, 1999).

Wiredu, K., "The Akan Concept of Mind," in Ibadan Journal of Humanistic Studies, 3 (October 1983). 